\title{
Erratum to: Matrix Metalloproteinases in Parasitic Infections
}

Fabrizio Bruschi and Barbara Pinto

\section{Erratum to: \\ Chapter "Matrix Metalloproteinases in Parasitic Infections" in: S. Chakraborti and N.S. Dhalla (eds.), \\ Pathophysiological Aspects of Proteases, https://doi.org/10.1007/978-981-10-6141-7_14}

The original version of the book was inadvertently published without updating the order of the reference list provided by author, which has been now corrected in chapter "Matrix Metalloproteinases in Parasitic Infections". The erratum chapter and the book have been updated with the change.

The updated online version of this chapter can be found at https://doi.org/10.1007/978-981-10-6141-7_14 